\title{
Móviles y pantallas en edades tempranas: convivencia digital, derechos de la infancia y responsabilidad adulta
}

Mobile phones and screens at an early age: digital coexistence, children's rights and adult responsibility

Mòbils i pantalles en edats primerenques: convivència digital, drets dels xiquets

i responsabilitat dels adults

\author{
Mari Carmen Caldeiro Pedreira ${ }^{1, *}{ }^{\circledR}$, Ana Castro Zubizarreta ${ }^{2}{ }^{\circledR}$, Teresa \\ Havránková ${ }^{3}$
}

Cómo citar: Caldeiro Pedreira, M-C; Castro Zubizarreta, A.; y Havránková, T. (2021). Móviles y pantallas en edades tempranas: convivencia digital, derechos de la infancia y responsabilidad adulta. Research in Education and Learning Innovation Archives, 26,1-17. 10.7203/realia.26.15936

Copyright: El/La Autor/a. Open Access: Este es un artículo de acceso abierto distribuido bajo los términos de la licencia Creative Commons Attribution-NoDerivatives 4.0 International licence (CC BY-ND 4.0)

Financiación: 'Alfamed' (Red Euroamericana de Investigadores), con el apoyo del Proyecto I+D " Youtubers e Instagrammers: la competencia mediática en los prosumidores emergentes" (RTI2018-093303-B-I00), financiado por la Agencia Estatal de Investigación del Ministerio de Ciencia, Innovación y Universidades de España y el Fondo Europeo de Desarrollo Regional (FEDER).

\author{
1 | Departamento de Pedagogía y Didáctica.Facultat de Facultad de Formación del Profesorado, Universidad \\ de Santiago de Compostela, Santiago de Compostela, Galicia, España \\ 2 | Facultad de Educación, Universidad de Cantabria, Santander, Cantabria, España \\ 3 | University of West Bohemia, República Checa \\ *Autor para correspondencia: mcarmen.caldeiro@usc.es (Mari Carmen Caldeiro Pedreira)
}

Recibido: 16/10/2019 | Aceptado: 20/05/2020 | Publicado: 20/01/2021

RESUMEN: En la sociedad hipermedia donde predomina el uso indiscriminado de múltiples pantallas desde edades cada vez más tempranas, es necesaria no solo la convivencia digital, sino además el respeto a los derechos de la infancia. Aspectos a los que debe unirse la responsabilidad por parte de los medios y también de las familias que educan a los menores. En este contexto surge esta investigación donde se revisa la literatura existente y se identifican dos planteamientos diferentes en torno a los dispositivos móviles e infancia; el referido a usos y posibilidades educativas y de enriquecimiento personal para los pequeños y, el que apunta usos abusivos y problemas derivados de su utilización. Este estudio de corte teórico muestra una revisión y reflexión basada en las ideas de un importante conjunto de autores que, en la era digital cuando la sociedad en general y de forma concreta la infancia utilizan la tecnología, apuestan por el empoderamiento del niño para convertirle en un receptor crítico. Por tanto, teniendo en cuenta que la infancia convive con los medios y que existen diferentes niveles de actividad de los niños frente a estos, se plantea una propuesta de niveles centrada en la actividad, la creación y la crítica social. Una propuesta que es posible alcanzar teniendo en cuenta la educación en, con y para los medios. Así mismo, en el marco de la CDN se propone que familias y escuelas potencien un uso adecuado de medios y pantallas por parte de la infancia.

PALABRAS CLAVE: era digital; infancia; derechos; convivencia mediática

ABSTRACT: In the hypermedia society the indiscriminate use of multiple screens is observed from an increasingly early age. For this reason, digital coexistence, respect for children's rights, and a sense of responsibility from the media and from families who educate children are required. This study reviews the literature in this field and identifies two approaches to the use of mobile devices in childhood. One approach highlights the uses of such devices as well as the opportunities they provide for children's education and personal enrichment, whereas the other highlights their abusive uses and the problems caused by using them. This theoretical study reviews and reflects on the ideas of numerous authors who - in this digital age when society in general and children in particular are using technology - are committed to empowering children to become critical receptors. 
Bearing in mind that childhood and the media cohabit the same space and that different children are engaged in different levels of media activity, we propose a range of levels that are based on activity, creation and social criticism. This proposal is achievable if we take into account education in, with and for the media. The CRC also recommends that families and schools should encourage suitable media and screen use by children.

KEYWORDS: digital age; childhood; rights; media coexistence

RESUM: En la societat hipermediàtica en què predomina l'ús indiscriminat de múltiples pantalles des d'edats cada vegada més primerenques és necessària no sols la convivència digital, sinó a més el respecte dels drets dels xiquets. Aspectes als quals ha d'unir-se la responsabilitat dels mitjans i també de les famílies que eduquen els menors. En aquest context sorgeix aquesta investigació en què es revisa la literatura existent i s'identifiquen dos plantejaments diferents sobre els dispositius mòbils i els xiquets; el referit a usos i possibilitats educatives i d'enriquiment personal per als xiquets i el que apunta usos abusius i problemes derivats de la seua utilització. Aquest estudi de tall teòric mostra una revisió i reflexió basada en les idees d'un important conjunt d'autors que en l'era digital, quan la societat en general i de manera concreta els xiquets utilitzen la tecnologia, aposten per l'apoderament del xiquet per convertir-lo en un receptor crític. Per tant, tenint en compte que els xiquets conviuen amb els mitjans $i$ que hi ha diferents nivells d'activitat dels xiquets enfront d'aquests, es planteja una proposta de nivells centrada en l'activitat, la creació i la crítica social. Una proposta que és possible posar en pràctica tenint en compte l'educació sobre, amb i per als mitjans. Així mateix, en el marc de la CDX es proposa que famílies i escoles potencien un ús adequat de mitjans i pantalles per part dels xiquets.

PARAULES CLAU: era digital; infància; drets; convivència mediàtica

\section{Notas de aplicación práctica}

\section{Qué se sabe sobre el tema}

- En la sociedad hipermedia predomina el uso indiscriminado de pantallas desde edades cada vez más tempranas.

- La infancia convive con los medios y existen diferentes niveles de actividad de los niños frente a estos.

- Los menores tienen derecho a acceder a la información en las mejores condiciones posibles.

\section{Qué aporta este trabajo}

- Una revisión de la literatura existente.

- Una identificación planteamientos en torno a los dispositivos móviles e infancia.

- Una apuesta por el empoderamiento del niño para convertirle en un receptor crítico.

- Cuatro categorías principales de uso y manejo de dispositivos móviles por parte de la infancia: los móviles y su función lúdica, los móviles y las aplicaciones educativas, los móviles como chupetes electrónicos o niñera digital y los móviles y su uso abusivo.

- Diferentes niveles de actividad de la infancia ante los medios.

Implicaciones para la práctica y / o política

- Se propone una propuesta de niveles centrada en la actividad, la creación y la crítica social.

- Se propone, en el marco de la CDN, que familias y escuelas potencien un uso adecuado de medios y pantallas por parte de la infancia.

\section{INTRODUCCIÓN. LA INFANCIA DEL SIGLO XXI EN LA ERA HIPERMEDIA: UNA CONVIVENCIA DIGITAL}

A lo largo de los últimos años la tecnología y las pantallas se han adueñado de la vida de la ciudadanía en general e independientemente de su rango de edad, el uso de herramientas tecnológicas se ha generalizado. Según recoge Telefónica en el Informe de la Sociedad de la Información (Telefónica, 2016) en España el 80\% de la población 
utiliza Internet y la cifra continúa incrementándose. En este contexto, no solo la población de edad media sino además, los menores y también las personas de mayor edad contribuyen al acelerado crecimiento de la cifra pues, tal y como expresa Geser:

"El uso de dispositivos móviles ha tenido una penetración horizontal y vertical entre la población, trascendiendo la pertenencia de clase, [...] las diferencias de género y generacionales, el grupo étnico o el capital cultural”.

(2004)

En este sentido y atendiendo al colectivo de la infancia, más allá de las cifras, interesa analizar el uso y/o el abuso que el colectivo de menor edad realiza de las pantallas. Además de ello, centra la atención la innegable convivencia, derivada de la realidad mediática que puede atribuirse al uso a factores externos en los cuales la familia juega un papel decisivo. Junto con la escuela, deben ejercer un control y deben contar con los conocimientos mínimos que la situación exige, conocimientos que les permiten comunicarse e interactuar en la sociedad digital más reciente. En la función de adultos se conjuga por tanto una doble vertiente: la normativa y la cognitiva entendiendo que esta última es compartida con los más pequeños en tanto que la «Generación $Z$ » a la que Atrevia en su Web denomina como «Autodidactas, creativos y sobreexpuestos a la información»son niños y niñas que cada vez de forma más temprana conocen el funcionamiento de las herramientas tecnológicas; sin embargo, en esta dimensión cognitiva son los adultos los que poseen una madurez superior que les permite interactuar y comunicarse de forma adecuada en la virtualidad.

La postmodernidad ha cambiado el sentido de la experiencia pero no sólo para introducir tolerancia, diversidad y respeto, sino también pensamiento debilitado, asociado a una experiencia espectacularizada de lo real, transformada en puro entretenimiento.

En esta era hipermedia, la convivencia de los niños con medios y pantallas es incuestionable. Concretamente, la pasión de los más pequeños por los dispositivos móviles es una realidad recogida en múltiples publicaciones a nivel internacional (Haddon y Vincent, 2014; Mascheroni y Ólafsson, 2014) que reflejan que la edad de inicio y acceso a estos dispositivos es cada vez más temprana. Teniendo en consideración los datos aportados en el trabajo de Kabali et al. (2015) en Estados Unidos, en el año 2013 el 72\% de los niños de 0 a 8 años utilizaban un dispositivo móvil frente al 38\% en 2011. La cifra representa un aumento significativo de acceso del que llama especialmente la atención el incremento de su uso en los niños menores de dos años (38\% en el año 2013). Los datos en el contexto nacional constatan esta tendencia internacional pues, los niños de 2-3 años utilizan habitualmente el móvil de sus padres para manejar aplicaciones como videos o juegos (Ditrendia 2017, 15). Así lo muestra también Roca (2015) en el Informe FAROS del Observatorio de Salud de la Infancia y la Adolescencia, dependiente del Hospital Sant Joan de Déu de Esplugues donde se especifica que un 40\% de la población menor de dos años utiliza tablets y móviles. En esta línea, la literatura internacional coincide en señalar que la edad en la que los niños utilizaron por primera vez un dispositivo móvil disminuye con cada cohorte de edad sucesiva (Haddon y Vincent, 2014; Mascheroni y Ólafsson, 2014).

Siguiendo a Chaudron (2015) solo un pequeño porcentaje de estudios han puesto el foco de atención en el uso de las tecnologías por los niños menores de 9 años. En esta línea contamos con investigaciones de carácter internacional (Haddon y Vincent, 2014; Holloway, Green, y Livingstone, 2013; Kabali et al., 2015; Marsh, 2014; Mascheroni y Ólafsson, 2014; Plowman y McPake, 2013; Plowman, Stevenson, Stephen, y McPake, 2012) no obstante en el contexto español son más escasas. En este ámbito llama la atención el estudio de Garmendia, Jiménez, Casado, y Mascheroni (2016) referido al proyecto internacional Net Children Go Mobile en el que han participado: Dinamarca, 
Italia, Reino Unido y Rumanía, Bélgica, Irlanda, Portugal y España, en este último participaron 500 menores de entre 9 y 16 años. Pese a todo, en España no existe un gran número de estudios sobre el uso de dispositivos móviles por parte de la población menor de 9 años.

En definitiva, la escasez de estudios que abordan la relación de la primera infancia con pantallas y dispositivos móviles dificulta la identificación de apreciaciones completas y precisas sobre la relación de los niños con dichos dispositivos, el valor simbólico atribuido por estos al objeto en cuestión, los contextos a los que tienen acceso o los efectos de esta tecnología en su vida personal, familiar y en su aprendizaje.

\subsection{Derechos de la infancia y medios de comunicación}

A nivel legislativo y normativo destaca la Convención de los Derechos del Niño (Convención de los Derechos del Niño, 1989) que recoge el potencial de los medios y su presencia e influencia; por su parte reivindica el rol activo que debe poseer la infancia en los contextos en los que se desarrolla, se relaciona y aprende (Dalhberg, Moss, y Pence, 1999; Harcourt, 2011; Pascal y Bertram, 2009). Además de ello, la Convención propulsó un cambio en el concepto de infancia que transita desde el paradigma de la dependencia al de la autonomía, donde los pequeños son ciudadanos capaces, con intereses propios, con derechos y con capacidad de acción y decisión que han que tener oportunidades de expresarse y participar en los contextos donde se desenvuelven.

La influencia de los medios se recoge además en el artículo 17 de la CDN, donde los Estados Partes reconocen la importante función que desempeñan los medios de comunicación y se plantea el papel de los medios en la difusión de información destinada a los niños. Asimismo se hace referencia a que velarán porque estos tengan acceso a información y material procedentes de diversas fuentes nacionales e internacionales, en especial, la información y el material que tengan por finalidad promover su bienestar social, espiritual y moral y su salud física y mental. Con tal objeto, los Estados Partes:

- Alentarán a los medios de comunicación a difundir información y materiales de interés social y cultural para el niño, de conformidad con el espíritu del artículo 29;

- Promoverán la cooperación internacional en la producción, el intercambio y la difusión de esa información y esos materiales procedentes de diversas fuentes culturales, nacionales e internacionales;

- Alentarán la producción y difusión de libros para niños;

- Alentarán a los medios de comunicación a que tengan particularmente en cuenta las necesidades lingüísticas del niño perteneciente a un grupo minoritario o que sea indígena;

- Promoverán la elaboración de directrices apropiadas para proteger al niño contra toda información y material perjudicial para su bienestar, teniendo en cuenta las disposiciones de los artículos 13 y 18.

En este sentido, Verhellen (2002), señala cómo se pueden establecer conexiones entre el binomio información y participación, ampliamente abordado a través de los artículos 12 y 13 que inciden en la necesidad de garantizar en el niño la formación de un juicio propio y el derecho a expresar su opinión libremente en todos los asuntos que le afectan, teniéndose debidamente en cuenta las opiniones del niño, en función de su edad y madurez. Del mismo modo, se recoge en el artículo 17 el ejercicio del derecho de buscar, recibir y difundir informaciones e ideas de todo tipo, sin consideración de fronteras, ya sea oralmente, por escrito o impresas, en forma artística o por cualquier otro medio elegido por el niño. Por otro lado, el artículo 16 hace referencia al derecho a la privacidad infantil, incluso en relación con sus progenitores. Unos y otros conducen, 
de forma inequívoca, al derecho a la participación del niño ante los medios, donde los pequeños sean capaces de expresar, de múltiples formas o lenguajes, su visión particular sobre temáticas de interés, visibilizando a una infancia silenciada bajo el poder del adulto.

Por ello la Convención insta a que los medios de comunicación difundan información y materiales de interés social y cultural para el niño y que se aliente la producción y difusión de libros y recursos para las audiencia infantiles entre otros aspectos (Chacón, 2006). En todo caso, la Convención de los Derechos del Niño abre el debate de la influencia de los medios en la infancia, la presencia de los niños en ellos y su uso por parte de los pequeños. Esto hace que, desde el marco internacional, se sienten las bases para pensar los medios bajo el enfoque de los derechos, lo que plantea la necesidad de ofrecer contenidos de calidad adecuados a la infancia, de abrir canales de participación, expresión y representación de una infancia que se sienta identificada con la imagen que se proyecta de ella a través de los medios.

En definitiva, y teniendo en cuenta el innegable contacto de los más pequeños con las pantallas, la Convención plantea la necesidad de ofrecer al niño pantallas, contenidos e informaciones donde se sientan representados y donde como colectivo tengan una presencia real y poderosa. Así recoge la Figura 1 una síntesis de los derechos de la infancia y su vinculación con los medios de comunicación.

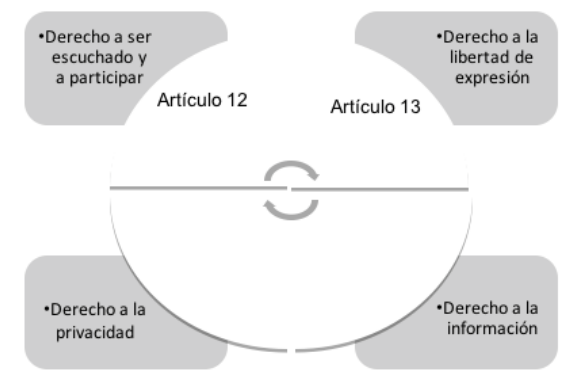

Figura 1. Síntesis de los derechos de la infancia y su vinculación con los medios de comunicación

Los menores tienen derecho a acceder a la información en las mejores condiciones posibles, a formar parte activa de la sociedad, lo cual implica el derecho a la libertad de expresión, a la información sin manipulación, al uso de recursos adecuados a su edad y formación. Todo ello requiere un proceso de aprendizaje que debe acometer la familia y la escuela como entidad responsable de la educación obligatoria, para lograr una ciudadanía mediática, autónoma (Gozálvez, 2013). Hecho que debe estimularse desde la familia y la escuela que han de activar la mente, infundir valor y coraje e inconformismo informado, y enseñar apertura a la pluralidad, al contraste de ópticas diferentes a la propia.

En este sentido, la educación mediática debiera estar presente en el marco de la Educación Infantil ya que sentará las bases para no solo la recepción de información sino para en un futuro una interpretación crítica y una producción responsable y cívica, en definitiva, un buen uso de los medios. Desde esta etapa se forma a «prosumidores» (García-Ruiz, Ramírez-García, y Rodríguez-Rosell, 2014) que, dada la situación existente han de convertirse en «prodiseñadores» (Hernández-Serrano, Renés-Arellano, Graham, y Greenhill, 2017). Para ello son clave los artículos de la Convención sobre los Derechos del Niño que tratan sobre comunicación y libertad de expresión $(12,13,17)$, reconocen la necesidad de concebir a la infancia como un colectivo al que hay que dar voz- incluso en los medios de comunicación -, así como 
porqué desde esta Carta Magna se insta a que los Estados Partes pongan en práctica políticas capaces de garantizar medios de comunicación de calidad, en las formas previstas por el documento.

El enfoque de derechos supone la creación de espacios que permitan el desarrollo personal y colectivo, y obliga a los adultos a replantear su rol y las relaciones que tejen con los niños con el objeto de establecer relaciones de igualdad como auténticos sujetos de derechos que son. Además, la Observación general número 1 formulada por el Comité de expertos de Naciones Unidas en el 2001 señala que, "los niños también deben aprender lo que son los derechos observando su aplicación en la práctica, ya sea en el hogar, en la escuela y/o en la comunidad. La educación en derechos humanos comienza con las experiencias de los niños/niñas." Una orientación que pone de relieve la importancia y el papel que poseen la familia y escuela como responsables de promover el desarrollo de la competencia mediática de los niños.

En esta línea, treinta años después de la formulación de esta Carta Magna, los derechos de la infancia siguen sin ser totalmente ejercidos y lo que es más preocupante, tal y como señala Maurás (2013) "la Convención sobre los Derechos del Niño es escasamente conocida entre los profesionales de la comunicación, tanto en términos de su contenido como de su significado para el trabajo de los medios".

El desafío, por tanto, consiste en poner en práctica y hacer efectivos estos discursos en las actuaciones directas con los niños, en orientarlos y apoyarlos para favorecer su desarrollo personal y colectivo, creando desde el contexto familiar y escolar espacios de ejercicio de derechos y de práctica ciudadana. Esto requiere que los adultos establezcan relaciones simétricas, de igualdad y colaboración con los niños.

\subsection{Objetivos de la investigación}

Teniendo en cuenta la situación actual y la relación de los menores con las pantallas, en esta investigación, se revisa la literatura existente que identificamos con dos planteamientos diferentes en torno a los dispositivos móviles e infancia:

- el que plantea usos y posibilidades educativas y de enriquecimiento personal para los pequeños y,

- el que apunta usos abusivos y problemas derivados de su utilización.

En este sentido, podemos inferir cuatro categorías principales de uso y manejo de dispositivos móviles por parte de la infancia presentes en la Figura 2: los móviles y su función lúdica, los móviles y las aplicaciones educativas, los móviles como chupetes electrónicos o niñera digital y los móviles y su uso abusivo.

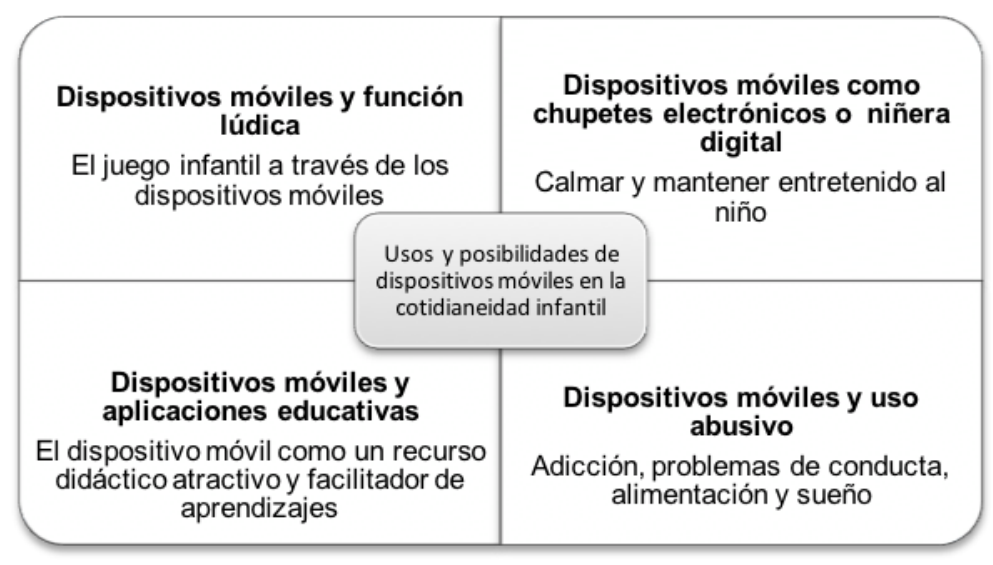

Figura 2. Categorías de uso y manejo de dispositivos móviles por parte de la infancia 
En la actualidad existen diferentes trabajos centrados en explicar los usos y las potencialidades de los móviles en el contexto infantil. Frente a las visiones que apuestan por centrar la atención en el uso meramente lúdico, estudios como Kabali et al. (2015) en Estados Unidos, identifican la exposición y uso de dispositivos móviles por parte de los más pequeños a través de una encuesta dirigida a familias con hijos con edades comprendidas entre los 4 meses y 4 años. Los resultados derivados de la investigación confirman que los progenitores permiten el acceso a los niños cada vez en edades más tempranas con la finalidad de que jueguen (70\%), mantenerles en calma en lugares públicos $(65 \%)$ e incluso, para que el niño se duerma (28\%). Un dato a tener en cuenta y que se desprende de este estudio es que casi la mitad de los hijos mayores de un año de las familias participantes $(43,5 \%)$ utilizaban el dispositivo móvil a diario siendo youtube la aplicación más utilizada por este colectivo infantil. Otro dato también sorprendente es que el 38\% de los niños americanos con edades inferiores a los dos años utilizan Smartphone y Tablets de forma habitual y el hecho de que el $75 \%$ de los niños menores de 8 años dispone de un dispositivo móvil. En el caso de España, la edad media en la que un niño tiene su primer smartphone es mayor, a los doce años (Garmendia et al., 2016).

Chaudron (2015) se refiere a menores de 8 años y destaca que, las familias tienden a posponer sus preocupaciones y precauciones sobre el uso de los dispositivos móviles por parte de los niños más pequeños ya que consideran que el escaso desarrollo de habilidades instrumentales básicas (lectura y escritura) les hace estar más protegidos ante posibles interacciones peligrosas a través del uso de la red o bien, otros posibles mensajes inapropiados o perjudiciales.

En su estudio, se acuña el término móvil como «chupete electrónico», al señalar que las familias están confiriendo esta función a este dispositivo digital que cumple desde su perspectiva, el propósito de calmar al pequeño y mantenerle entretenido a la vez que incluso, se describe que se proporciona el acceso a los pequeños a estos para que los adultos puedan disfrutar de su propio tiempo personal. Es así como deben entretenerse de formas no siempre propias de su edad; en ocasiones los dispositivos tecnológicos se convierten por un momento en «niñera digital» (García-Rodríguez y Gómez-Díaz, 2016); es decir, elementos que los menores utilizan de manera inadecuada en su tiempo de ocio, mientras los mayores atienden a su trabajo o simplemente se comunican a través de las tecnologías más recientes.

Asimismo, en las investigaciones que abordan el uso de dispositivos móviles por parte de los niños existe una tendencia a evidenciar los peligros o problemas derivados de su uso por parte de la población infantil, quedando escasamente explorados posibles beneficios de este uso en el campo educativo o bien en el desarrollo personal. En relación a los efectos negativos, Hardell (2018) afirma que los teléfonos móviles y teléfonos inalámbricos emiten radiación de radiofrecuencia (RF). Una radiación a la que ninguna generación ha sido expuesta durante su infancia y adolescencia con anterioridad. También señala otros posibles problemas derivados de una exposición y uso de estos dispositivos tan precoz, como trastornos del sueño y problemas de conducta provocados por la adicción a su manejo. Pediathrics (2014) señala que el uso desproporcionado de la tecnología por parte de los niños puede favorecer una mala alimentación ya que los pequeños comen menos o más rápido para disponer de más tiempo frente a las pantallas. INTECO (2009) identifica peligros asociados al uso de los dispositivos móviles por parte de los pequeños, como el acceso a contenido inapropiado para su edad, la vulneración del derecho a su privacidad, y el acecho por parte de otras personas. Desde esta perspectiva que recoge los riesgos asociados al uso de los medios tecnológicos por parte de la población infantil, encontramos estudios centrados en la supervisión o protección que los referentes adultos brindan a los niños ante su acceso al mundo digital. Estos estudios (Gasser, Maclay, y Palfrey, 2010; Livingstone y Bulger, 2013; UNICEF, 2011) sugieren que los niños suelen estar solos 
en el mundo digital, sin una infraestructura de apoyo dentro de sus familias o comunidades, o un entorno regulatorio que garantice sus derechos a un uso seguro y acceso a oportunidades. En este sentido identifica Madigan, Browne, Racine, Mori, y Tough (2019) una relación negativa entre pasar demasiadas horas frente a las pantallas y tener un peor desarrollo infantil. Estas aportaciones contrarias al uso de dispositivos móviles por parte de los más pequeños infieren una apuesta por la cautela y la protección. Sin embargo, frente a ellas, otras como la realizada por Vittrup, Snider, Rose, y Rippy (2014) en Estados Unidos reflejan cómo las familias siguen considerando positivo el acceso de sus hijos con edades inferiores a los seis años a múltiples dispositivos tecnológicos, aun recibiendo información por parte de expertos en educación y salud que desaconseja esta actuación.

Los aspectos positivos han sido descritos en el marco de la educación obligatoria, pero constan resultados de su aplicación en la Educación Infantil. A partir de los 6 años, inicio de la Educación Primaria, se describen experiencias (Aw, Wong, Zhang, Li, y Quek, 2016; Fokides y Atsikpasi, 2017; Lai, Lai, Chuang, y Wu, 2015) que recogen en sus resultados mejora de la motivación de los estudiantes y en su rendimiento académico. Los niños más pequeños tienen acceso al uso de dispositivos móviles en el contexto familiar, no en el escolar donde su uso tiende a estar restringido. Desde la familia se proveen tiempos de uso. Al respecto, Kabali et al. (2015), señala que el $52 \%$ de los padres descargan aplicaciones educativas para sus hijos en los móviles lo que pone de relieve el potencial educativo que las familias perciben en estos dispositivos para los más pequeños, resultados coincidentes con los ya apuntados por Vittrup et al. (2014).

En todo caso, es posible hacer referencia a un resurgir de la polémica o el debate académico en torno a medios y pantallas y su presencia y convivencia con los más pequeños, al igual que ya sucedió en su momento con la televisión, también denominada «niñera electrónica». En este punto:

Parece claro que para comprender el impacto y el efecto de la televisión sobre los niños debemos, antes que nada, abandonar el concepto no realista de lo que la televisión 'hace a los niños' y sustituirlo por aquel de lo que los niños hacen con la televisión

(Farné 2008, 16)

Por tanto, resulta clave trasladar tal afirmación a lo que actualmente está sucediendo con los dispositivos móviles, considerando la necesidad imperante en nuestro contexto de investigar qué es lo que los niños hacen con los móviles en la actualidad y qué es lo que está motivando realmente el uso de estos dispositivos por parte de los más pequeños.

\section{METOdOLOGÍA}

Este estudio de corte teórico muestra una revisión y reflexión basada en las ideas de un importante conjunto de autores que, en la era digital cuando la sociedad en general y de forma concreta la infancia utilizan la tecnología, apuestan por el empoderamiento del niño para convertirle en un receptor crítico. Autores de reconocido prestigio en el ámbito infantil que abogan por criterios como el de visilibización de la infancia y responsabilidad adulta como factores clave a la hora de posibilitar la convivencia de la infancia y los medios.

Esta investigación gestiona la revisión de las ideas sin utilizar estadísticos para llevar a cabo la fundamentación de la tesis de Corraliza (2001) que apuesta por educar a la infancia para que se convierta en receptora crítica y activa. 


\section{RESULTADOS: NIVELES DE ACTIVIDAD DE LA INFANCIA ANTE LOS MEDIOS: DEL NIÑO COMO RECEPTOR PASIVO AL NIÑO COMO CRÍTICO SOCIAL}

La infancia convive con medios, los manejan como nativos digitales que son y, construyen su identidad personal a través de ellos, explorando, descubriendo y conociendo. Existen diferentes niveles de actividad de los niños frente a los medios; estadios descritos por autores como Martínez-Toda (1998) o Marta-Lazo (2005) quienes señalan que las persona pasamos por diferentes niveles o estadios dentro de un proceso continuo que conlleva como último nivel el que el sujeto se convierta en "creativo" o creador de contenidos en el caso de la propuesta de Martínez Toda o, «perceptor participante» en los niveles de actividad sugeridos por Marta-Lazo.

Dichas escalas quedan reflejadas en la Figura 3 que recoge una propuesta centrada en los niveles: receptor pasivo, receptor activo, creador y crítico social desde una perspectiva integradora.

\begin{tabular}{|l|}
\hline Martínez Toda (1998) \\
\hline -Alfabetizado \\
- Consciente \\
- Activo \\
- Crítico \\
- Social \\
- Creativo \\
\hline
\end{tabular}

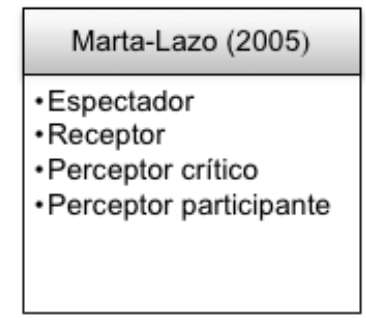

\section{Propuesta propia}

- Receptor pasivo

- Receptor activo

- Creador

- Crítico socia

Figura 3. Propuesta de niveles

El primer nivel, corresponde al niño como receptor pasivo, lo que supone presentar al pequeño como un espectador que, fijado ante la pantalla visualiza el contenido que se emite. Este primer estadio (Marta-Lazo, 2005) requiere un nivel de actividad mínimo, si bien, los mensajes que reciben los pequeños dejan huella en su persona, incidiendo en la manera que tienen de entender y conferir significados al mundo que les rodea si no es de manera inmediata en un futuro próximo.

En el segundo nivel, receptor activo, el niño manifiesta sus gustos e intereses en torno a lo que visualiza. Elige la actividad que quiere realizar a través de un dispositivo móvil o ver en la pantalla. En el tercer nivel, creador, el niño no decide qué ver o elegir según sus preferencias, y desde el manejo de dispositivos móviles tiene la posibilidad de crear contenido, como fotografías, grabaciones, textos a través de mensajería instantánea que intercambia en un contexto comunicativo, el virtual, que se abre ante él posibilitando oportunidades de interacción, de ser y de estar. Es decir, se aproxima al prosumidor, (Toffler, 1980) que debe desarrollar la capacidad de producir contenidos. En este punto enlaza con el cuarto nivel, crítico social, que favorece la promoción de una ciudadanía capaz de consumir y producir contenidos mediáticos que redunde en personas competentes para realizarlo con responsabilidad, ética y cuidado. Personas que desarrollen la mirada crítica (Caldeiro-Pedreira, 2014) ante la dieta mediática que se oferta.

En este sentido familia y escuela han de primar la alfabetización mediática adecuada y de calidad, (Pérez-Escoda, García-Ruiz, y Aguaded, 2018) enfocada a una educación con medios, en medios y una educación ante los medios, (Bernabeu, 2010), y que se erigen como ejes de actuación (véase Figura 4) para el desarrollo de la competencia mediática. 


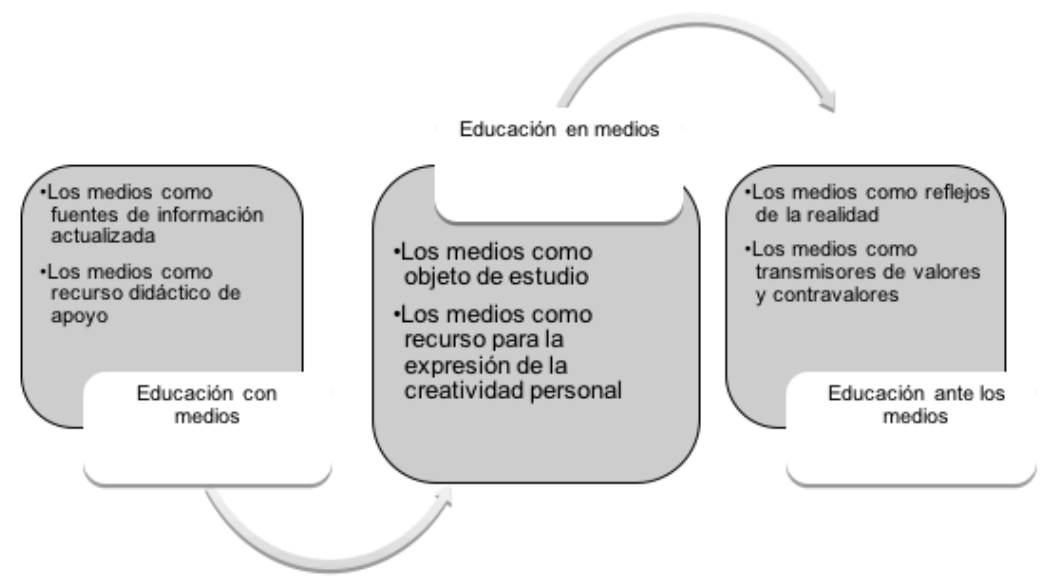

Figura 4. Ejes de actuación

La educación con medios supone desde la perspectiva de Bernabeu (2010), la utilización de estos como fuente de información y documentación y recurso didáctico. Se trata de una educación que debe sustentarse en la convivencia de los niños con estos, teniendo en cuenta que, la exposición a medios y pantallas posee una funcionalidad educativa, es decir, la educación con medios ha de generar aprendizajes significativos y funcionales en los niños. En este caso, la función lúdica tendría un papel fundamental, no solo didáctico sino como medio de entretenimiento y de ocio, función que la infancia está otorgando a medios en general y, sobre todo, a dispositivos móviles.

La educación en medios, supondría el aprendizaje de los conceptos básicos de la competencia mediática ya que se convierten desde este eje pedagógico en objeto de estudio cuyos contenidos aparecen reflejados en los de las diferentes áreas o materias, constituyéndose como recurso para la expresión de la creatividad personal a través de su dominio y comprensión.

La educación ante los medios supondría el desarrollo en los niños de la habilidad reflexiva, que les ayude a desarrollar una mirada crítica ante los medios, fomentando actitudes positivas y posturas activas y comprometidas proclives al desarrollo de una ciudadanía participativa, ética y democrática.

La propuesta de niveles de actividad infantil frente a los medios y los ejes pedagógicos sugeridos por Bernabeu (2010) se puede ver reflejado en la Figura 5, -el niño evoluciona desde receptor activo con el eje pedagógico de educación con medios, a creador con la educación en medios y, a niño como crítico social, con la educación ante los medios-. El hecho de no vincular el primer nivel de actividad, el niño como receptor pasivo, con ningún eje pedagógico es porque se entiende que este estadio supone el punto de partida promovido por una sociedad tecnologizada y de la información a partir del cual la educación mediática a través de los ejes pedagógicos expuestos interviene en el desarrollo óptimo de los infantes.

En tiempos de una modernidad "líquida, imprevisible y sin certezas" (Bauman, 2007) la educación mediática en las tres vertientes expuestas, posibilita que el niño, futuro ciudadano, desarrolle habilidades de análisis, sistematización, pensamiento crítico y creativo. Estudios, como el de Zhong (2011), han puesto en evidencia que, a pesar de que estamos constantemente expuestos a las pantallas y los medios, contamos con un mayor acceso a las tecnologías y las usamos cotidianamente, esto no garantiza que se hayan desarrollado las competencias necesarias para hacer un uso correcto en el 


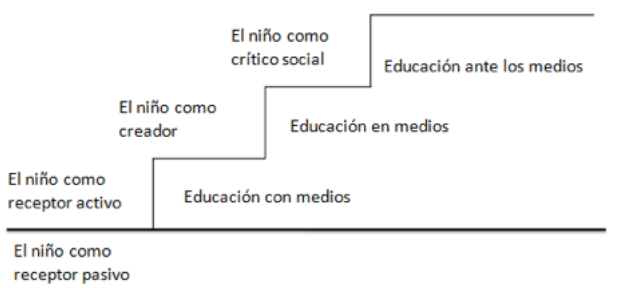

Figura 5. Evolución del niño

consumo de medios y en la producción de nuevos contenidos y mensajes. La competencia mediática, entendida como la capacidad para percibir, analizar y disfrutar del poder de los mensajes, imágenes, estímulos y sonidos que se perciben de los medios de comunicación, usándolos para satisfacer las necesidades de comunicación, expresión, formación o información que puedan generarse en diversas situaciones cotidianas (EU, 2009), se erige como una competencia básica a desarrollar en la ciudadanía que debe impulsarse desde edades tempranas.

\section{DISCUSIÓN}

Llegados a este punto conviene hacer hincapié en la perspectiva de la infancia sobre temas que afectan a su vida, un hecho que, como se ha podido apreciar a lo largo de esta investigación, se ha convertido en centro de atención de investigadores educativos. Resulta clave escuchar las opiniones de los niños y que estos sean tenidos en cuenta en los diferentes contextos en los que se desenvuelven. Un hecho que supone un desafío para la investigación educativa actual.

Según puede derivarse de los estudios indicados, la concepción de la infancia presentada se identifica con un colectivo competente, activo, con derechos, con capacidad de tomar decisiones y por lo tanto, de participar como ciudadanos (Harcourt y Einarsdóttir, 2011; Pascal y Bertram, 2009). En este sentido, los medios de comunicación presentan un gran potencial como canal para la participación de los niños en la vida pública sin embargo, en el ámbito de la investigación, si bien existen muchos estudios relacionados con los usos que hacen los niños de los medios y la influencia que estos tienen en la infancia, apenas hay investigaciones relativas a experiencias de producción de los niños como creadores de los contenidos". (Sotelo, Marta-Lazo, y Aranda, 2012). En la misma línea, Fielding (2011) y Messiou (2013) señalan que, además de contar con pocas experiencias de producción, la repercusión de estos estudios y actuaciones en la vida diaria de los niños es más bien limitada. Se trata de una línea de investigación en ciernes que amplía la visión que tiene el investigador sobre la realidad educativa al incluir una voz, la infantil, que ha tendido a ser silenciada frente a la visión hegemónica de los agentes educativos adultos, interlocutores e informantes por excelencia en la tradición investigadora (Castro, Ezquerra-Muñoz, y Argos-González, 2016)

Por su parte, el Comité de los Derechos del Niño, consagró el 7 de octubre de 1996 uno de sus debates a la cuestión del niño y los medios de comunicación. Este debate expresó la opinión de que, la prensa y otros medios de comunicación cumplen (o pueden cumplir) funciones esenciales en la promoción y protección de los derechos fundamentales del niño y en la puesta en práctica de los principios y las normas de la Convención. Además, hizo especial alusión a la posibilidad de que los medios de comunicación ofrecieran a los niños la oportunidad de expresarse y ser tenidos en cuenta. Para ello, debería promoverse el programa de UNICEF "La juventud opina" en 
la World Wide Web como foro infantil en Internet para el debate internacional sobre cuestiones relevantes para la juventud. Su desarrollo es escaso y lento lo que refleja cómo la perspectiva infantil sigue siendo infravalorada y silenciada.

En este sentido, no podemos obviar que determinadas experiencias o estudios reseñables recogen el rol protagónico infantil vinculado con los medios (Martínez-Garza, 2012). Asimismo, los resultados muestran cómo los niños participantes en el estudio no se identifican sino que cuestionan la imagen infantil presentada. Por su parte, ChacónGordillo (2011) aborda cómo interpretan los niños y niñas de Educación Infantil las Series y Películas de Animación y los Videojuegos, analizando su perspectiva a través del dibujo. El autor realiza un acercamiento al significado que dan los niños/as a los Referentes Culturales y Sociales procedentes de las imágenes de la Cultura Visual Infantil y a la forma en la que relacionan su propio contexto social y cultural con ellos.

Además, contamos con diferentes trabajos que muestran la perspectiva de la infancia sobre los medios, concretamente la publicidad (Montoya, Castro, y Aguaded, 2018). Son estudios y experiencias que favorecen la participación de los niños en investigaciones que tienen como objeto de estudio los medios, referidas a niños con edades superiores a los siete años, esto deja en desventaja a los niños con edades inferiores a la que determina la escolaridad obligatoria. Niños de 0-6 años que conviven con medios, interactúan con ellos y crecen con estos.

Por tanto, esto supondría un reto a la hora de contar con investigaciones que incorporen y acerquen experiencias de participación de los más pequeños con los medios, estudios que recojan su perspectiva, intereses y motivaciones. Investigaciones que indudablemente nos ayudarán a conocer mejor a la infancia.

Además de esto, no podemos olvidar que la investigación con niños debe tener presente la ética que ha de orientar el desarrollo de estudios donde el bienestar superior del niño, su seguridad, libertad y capacidad de decisión en torno a su participación en la investigación deben ser principios inalterables. Al respecto, Ortiz, Prats, y Baylina (2012) ofrecen una guía que puede servir de apoyo y cuyos elementos principales a tener en cuenta presentamos a continuación:

- Suministrar información clara del objetivo de estudio a las personas relacionadas con él (comunidad académica de colegio, directivas docentes, estudiantes).

- Informar del proceso a partir del cual se obtendrá información.

- Asegurar la confidencialidad y el anonimato de los participantes.

- Explicar a los niños las razones por las cuales se requiere su colaboración.

- Ofrecer a los niños de los grados seleccionados, la oportunidad de participar o no en el estudio (la decisión debe ser libre y sin coacción por parte de padres/madres o profesores e investigadores).

- Garantizar que todas las opiniones generadas del estudio serán respetadas y tomadas en cuenta seriamente.

- Explicar cómo se utilizará la información obtenida de los instrumentos realizados a los niños. Manifestar claramente que los niños son los actores sociales del estudio. Por lo tanto tendrán siempre toda consideración, prioridad y protagonismo.

Estas cuestiones éticas se vinculan a dos elementos fundamentales que es necesario tener en cuenta. En primer lugar, la importancia de la disminución de la disparidad de poder y estatus y de la hegemonía adulta: este condicionante ético invita a reconocer que los adultos poseemos una limitada compresión de las vidas y experiencias de la infancia (Clark y Moss, 2001), puesto que las experiencias infantiles del adulto no tienen por qué coincidir con las experiencias de la infancia actual. Esto supone acercarnos a la "simetría ética" (Christensen y Prout, 2002) que manifiesta la necesidad 
de interdependencia entre el adulto y el niño y lo valioso de las perspectivas de ambos para evitar la creación de sesgos ante una realidad en concreto.

En segundo lugar, conviene tener en cuenta el papel de la investigación educativa que requiere superar el acto consultivo y el derecho a que los niños pregunten y conozcan el uso que se hace de su perspectiva. Por ende, la recogida de la perspectiva infantil debiera contemplar una repercusión en la vida de los pequeños para mejorarla $\mathrm{y}$ atender, a las aportaciones, que en determinados temas reportan.

\section{CONCLUSIONES}

Los medios de comunicación y los móviles se utilizan, como se ha constatado en esta investigación, por parte de la infancia desde edades cada vez más tempranas. Así mismo, en la vida infantil tienen un potencial innegable y desempeñan un papel importante en la difusión de información destinada a los niños, en su capacidad de expresión y en la representación que de la infancia se proyecta a través de las pantallas. Al respecto, "los media han dejado de ser por su abrumador peso social un mero instrumento, para pasar a convertirse en condición de nuestra existencia específica, y en nuestro entorno social y cultural" (Pérez-Tornero, 2003).

En este sentido y teniendo en cuenta que la infancia convive con medios e interactúa a través de ellos cada vez más temprano es necesario un estudio profundo que ayude a comprender mejor la vida de los niños en la actualidad lo que posibilitará un mayor conocimiento de la infancia. Además de ello, urge establecer mecanismos que nos sirvan para velar por el adecuado uso de los medios y para ello, como se ha indicado anteriormente, la Convención de los Derechos del Niño se presenta como marco de referencia.

En este marco destacan los tres ejes fundamentales que propone la Convención de los Derechos del niño, es decir, los conocidos como las tres P: Provisión, Protección y Participación (Rodríguez et al., 2012). Estos pueden constituir el marco que oriente a familias y escuelas para potenciar un uso adecuado por parte de la infancia:

1. Provisión, entendido como acceso de los niños al uso de medios y pantallas;

2. Protección que en nuestro caso hace referencia a las condiciones de riesgo para la protección infantil y las garantías de supervisión y apoyo de las que los niños se sientan partícipes;

3. Participación, en el sentido de reconocer las preferencia infantiles sobre el uso de dichos dispositivos en su vida cotidiana y su presencia y toma de decisiones sobre las actividades de ocio en su tiempo libre, además de entender la participación de los niños como informantes en posibles investigaciones que deseen empoderar a la infancia.

Por último conviene señalar que el desarrollo de prácticas que promuevan los derechos de los niños ante los medios y su uso adecuado y responsable se convierte en un reto para la educación del siglo XXI. Un desafío incuestionable e irrenunciable que podrá alcanzarse apelando a la formación de una ciudadanía prosumidora, participativa y democrática que requiere sumar esfuerzos por parte de todos los agentes educativos adultos implicados en la educación de la infancia. Una educación que tiene que acometerse en un marco de escucha, diálogo y participación donde los pequeños puedan expresarse, sentirse representados y escuchados, en la línea de lo que plantea la CDN. Se trata de una educación que, desde edades tempranas debe apostar por la alfabetización y el empoderamiento de la infancia. Una infancia que, como de ha indicado en la propuesta que se ofrece en esta investigación debe evolucionar desde el nivel inicial: niño como agente pasivo, hasta la cumbre: el niño como sujeto crítico. 
Para ello los "padres deben asegurarse de que los contenidos que ven tengan calidad, sean apropiados para ellos y, a poder ser, que contengan elementos interactivos para evitar la pasividad" (Caixabank, 2020).

Esta tarea compete a los diferentes agentes formativos: familias y escuela y también a los propios medios. En este sentido, "El papel de los padres es fundamental para que los niños adquieran hábitos tecnológicos saludables” (Rojín, 2020).

Se hace hincapié además en la importancia de la legislación actual que hace referencia, en el marco general y de forma concreta en casos específicos, al respeto a los derechos del niño así como a la necesidad de darles voz y visibilizarlos en el contexto digital en el que se desarrollan.

En este sentido las experiencias de juego, aprendizaje, participación y socialización tienen una vertiente digital, a pesar de que las familias, el profesorado y los legisladores no siempre comprenden los riesgos y oportunidades asociados a esto (Livingstone y Das, 2010). Por tanto, la Convención de las Naciones Unidas sobre los Derechos del Niño ha de actuar como un marco para aplicar a los derechos del niño en la era digital.

\section{REFERENCIAS}

Aw, G. P., Wong, L. H., Zhang, X., Li, Y., y Quek, G. H. (2016). MyCLOUD: A Seamless Chinese vocabulary learning experience mediated by cloud and mobile technologies. En C. S. Chai, C. P. Lim, y C. M. Tan (Eds.), Future Learning in Primary Schools - A Singapore Perspective (pp. 65-78). Singapore: Springer.

Bauman, Z. (2007). Los retos de la educación en la modernidad líquida. Barcelona: Gedisa. Bernabeu, N. (2010). La educación mediática en el currículo de la LOE : aportaciones de este ámbito de conocimiento a la educación por competencias básicas. Congreso Euro-Iberoamericano de Alfabetización Mediática y Culturas Digitales. Sevilla: Universidad de Sevilla. Descargado de https://idus.us.es/bitstream/handle/11441/ 56892/la_educacion_mediatica_en_el_curriculo_de_la_loe._aportaciones_de_este _ambito_de_conocimiento_a_la_educacion_por_competencias_basicas.pdf?sequence= $1 \&$ isAllowed $=\mathrm{y}$

Caixabank. (2020). Niños y pantallas: una visión didáctica de su uso. [Blog post]. Descargado de https://bit.ly/2Kfelkj

Caldeiro-Pedreira, M. C. (2014). Alfabetización comunicativa para el desarrollo de la autonomía moral : estudio de la competencia mediática en los adolescentes de Lugo (Galicia) (Tesis Doctoral, Universidad de Huelva, Huelva). Descargado de http:// rabida.uhu.es/dspace/handle/10272/9057

Castro, A., Ezquerra-Muñoz, P., y Argos-González, J. (2016). Procesos de escucha y participación de los niños en el marco de la educación infantil. Una revisión de la investigación . Educación XX1, 19(2), 105-126. https://dx.doi.org/10.5944/educxx1 .16455

Chacón, C. (2006). Participación social y voluntariado . En M. A. García y T. López (Eds.), Intervención social y comunitaria (pp. 115-117). Málaga: Aljibe.

Chacón-Gordillo, P. (2011). ¿Cómo interpretan los niños y niñas de Educación Infantil las Series y Películas de Animación y los Videojuegos? Un análisis a través del dibujo (Tesis Doctoral, Universidad de Granada, Granada). Descargado de http://hdl.handle.net/ $10481 / 18411$

Chaudron, S. (2015). Young Children (0-8) and digital technology: A qualitative exploratory study across seven countries. London: Institute for the Protection and Security of the Citizen.

Christensen, P., y Prout, A. (2002). Working with Ethical Symmetry in Social Research with Children. Childhood, 9(4), 477-497. Descargado de https://journals.sagepub.com/doi/ pdf/10.1177/0907568202009004007 
Clark, A., y Moss, P. (2001). Listening to Young Children: The Mosaic Approach. London: National Children's Bureau.

Convención de los Derechos del Niño. (1989). Descargado de https://www.ohchr.org/sp/ professionalinterest/pages/crc.aspx

Corraliza, J. A. (2001). El comportamiento humano y los problemas ambientales. Estudios de Psicología, 22(1), 3-9. https://doi.org/10.1174/021093901609541

Dalhberg, G., Moss, P., y Pence, A. (1999). Beyond Quality in Early Childhood Education and Care: Postmodern Perspectives. London and Philadelphia, PA: FalmerPress.

Ditrendia. (2017). Informe Mobile en España y en el mundo 2017. Descargado de https://bit.ly/ 2ogkwQ1

EU. (2009). Commission recommendation of 20 August 21011 on media literacy in the digital environment for a more competitive audiovisual and content industry and an inclusive knowledge society. Official fournal of the European Union, 227(9). Descargado de https://eur-lex.europa.eu/LexUriServ/LexUriServ.do?uri=OJ:L:2009:227:0009:0012:EN: PDF

Farné, R. (2008). El problema de la investigación sobre los niños y la televisión. Doxa Comunicación. Revista interdisciplinar de estudios de comunicación y ciencias sociales, 7(7), 13-24. https://dx.doi.org/10.31921/doxacom.n7a1

Fielding, M. (2011). La voz del alumnado y la inclusión educativa: una aproximación democrática radical para el aprendizaje intergeneracional. Revista Interuniversitaria de Formación del Profesorado, 70, 31-61. Descargado de https://dialnet.unirioja.es/ descarga/articulo/3426240.pdf

Fokides, E., y Atsikpasi, P. (2017). Redefining the Framework for Teaching Programming to Primary School Students: Results from Three Pilot Projects. British fournal of Education, Society \& Behavioural Science, 20(3), 1-11. https://doi.org/10.9734/BJESBS/ 2017/33520

García-Rodríguez, A., y Gómez-Díaz, R. (2016). Lectura digital infantil. Dispositivos, aplicaciones y contenidos. Barcelona: UOC.

García-Ruiz, R., Ramírez-García, A., y Rodríguez-Rosell, M. M. (2014). Media literacy education for a new prosumer citizenship. Comunicar, 22(43), 15-23.

Garmendia, M., Jiménez, E., Casado, M. A., y Mascheroni, G. (2016). Net Children Go Mobile: Riesgos y oportunidades en internet y el uso de dispositivos móviles entre menores españoles. Madrid: Red.es / Universidad del País Vasco.

Gasser, U., Maclay, C., y Palfrey, J. G. (2010). Working towards a deeper understanding of digital safety for children and young people in developing nations. Descargado de https:// dmlhub.net/wp-content/uploads/files/SSRN-id1628276.pdf

Geser, H. (2004). Towards a Sociological Theory of the Mobile Phone. Descargado de https:// nbn-resolving.org/urn:nbn:de:0168-ssoar-435529

Gozálvez, V. (2013). Ciudadanía mediática. Una mirada educativa [Mediaticcitizenship. An educational look]. Madrid: Dykinson.

Haddon, L., y Vincent, J. (Eds.). (2014). European children and their carers' understanding of use, risks and safety issues relating to convergent mobile media. Milano: Unicatt. Descargado de http://eprints.lse.ac.uk/60147/1/_lse.ac.uk_storage_LIBRARY _Secondary_libfile_shared_repository_Content_Net\%20Children\%20Go\%20Mobile\% 20Project_Reports_European\%20children\%20and\%20their\%20carers'\%20understanding 2014.pdf

Harcourt, D. (2011). An encounter with children: seeking meaning and understanding about childhood. European Early Childhood Education Research fournal, 19(3), 331-343.

Harcourt, D., y Einarsdóttir, J. (2011). Introducing children's perspectives and participation in research. European Early Childhood Education Research fournal, 19(3), 301-307. https:// doi.org/10.1080/1350293X.2011.597962

Hardell, L. (2018). Effects of Mobile Phones on Children's and Adolescents' Health: A Commentary. Child Dev, 89(1), 137-140. 
Hernández-Serrano, M., Renés-Arellano, P., Graham, G., y Greenhill, A. (2017). From prosumer to prodesigner: Participatory news consumption. Comunicar, 25(50), 77-88.

Holloway, D., Green, L., y Livingstone, S. (2013). Zero to Eight: Young Children and Their Internet Use. London: EU Kids Online.

INTECO. (2009). Estudio sobre hábitos seguros en el uso de las TIC por niños y adolescentes y econfianza de sus padres. Descargado de https://faros.hsjdbcn.org/sites/default/files/298 .1-estudio_habitos_seguros_menores_y_econfianza_padres_versionfinal_accesible.pdf

Kabali, H. K., Irigoyen, M. M., Nunez-Davis, R., Budacki, J. G., Mohanty, S. H., Leister, K. P., y Bonner, R. L. (2015). Exposure and Use of Mobile Media Devices by Young Children. Pediatrics, 136, 1044-1050.

Lai, A. F., Lai, H. Y., Chuang, W. H., y Wu, Z. H. (2015). Developing a mobile learning management system for outdoors nature science activities based on 5e learning cycle. International Conference e-Learning. Descargado de https://files.eric.ed.gov/fulltext/ ED562473.pdf

Livingstone, S., y Bulger, M. E. (2013). A global agenda for children's rights in the digital age: Recommendations for developing UNICEF's research strategy. Florence: UNICEF. Descargado de https://www.unicef-irc.org/publications/pdf/lse $\% 20 \mathrm{olol} \% 20$ final3.pdf

Livingstone, S., y Das, R. (2010). Changing media, changing families: Polis Media and Family series. Descargado de http://eprints.lse.ac.uk/30156/

Madigan, S., Browne, D., Racine, N., Mori, C., y Tough, S. (2019). Association Between Screen Time and Children's Performance on a Developmental Screening Test. FAMA Pediatr., 173, 244-250. https://doi.org/10.1001/jamapediatrics.2018.5056

Marsh, J. (2014). The relationship between online and offline play: Friendship and exclusion. En A. Burn y C. Richards (Eds.), Children's Games in the New Media Age. London: Ashgate.

Marta-Lazo, C. (2005). Análisis de la audiencia infantil : de receptores de la televisión a perceptores participantes (Tesis Doctoral). Descargado de https://eprints.ucm.es/id/ eprint/5464/1/T28490.pdf

Martínez-Garza, F. J. (2012). Derechos humanos y la televisión desde la perspectiva de los niños. Razón y palabra. Primera Revista Electrónica en América Latina Especializada en Comunicación. Descargado de http://www.razonypalabra.org.mx/N/N81/M81/17 _Martinez_M81.pdf

Martínez-Toda, J. (1998). El impacto moral y social de los medios de comunicación social. Comunicar(10), 164-170. https://doi.org/10.3916/C10-1998-25

Mascheroni, G., y Ólafsson, K. (2014). Net Children Go Mobile: cross-national comparisons. Milano: Educatt. Descargado de http://eprints.lse.ac.uk/59584/1/_lse.ac.uk_storage _LIBRARY_Secondary_libfile_shared_repository_Content_Net\%20Children\%20Go\% 20Mobile\%20Project_Reports_Crossnational\%20comparisons\%20report\%20D3.3_2014 .pdf

Maurás, M. (2013). Derechos del Niño y medios de comunicación. Madrid: Consejo Nacional de Televisión.

Messiou, K. (2013). El compromiso con la voz del alumnado: uso de un marco de trabajo para abordar la marginación en las escuelas. Revista de Investigación en Educación, 11(3), 97-108. Descargado de https://dialnet.unirioja.es/descarga/articulo/4735339.pdf

Montoya, P.-A. G., Castro, A., y Aguaded, I. (2018). La publicidad con ojos de niños: Imaginarios infantiles y construcción de significados. Aula abierta, 47(4), 471-480. https://doi.org/10.17811/rifie.47.4.2018.471-480

Ortiz, A., Prats, M., y Baylina, M. (2012). Métodos visuales y geografías de la infancia: dibujando el entorno cotidiano. Scripta Nova. Revista Electrónica de Geografía y Ciencias Sociales, XVI(400). Descargado de http://www.ub.edu/geocrit/sn/sn-400.htm

Pascal, C., y Bertram, T. (2009). Listening to young citizens: the struggle to make real a participatory paradigm in research with young children. European Early Childhood Education Research fournal, 17(2), 249-262. 
Pediathrics. (2014). Patterns of Mobile Device Use by Caregivers and Children During Meals in Fast Food Restaurants.

Pérez-Escoda, A., García-Ruiz, R., y Aguaded, I. (2018). La competencia mediática en el profesorado universitario. Validación de un instrumento de evaluación. @tic revista d'innovació educativa(21), 1-9. https://doi.org/10.7203/attic.21.12550

Pérez-Tornero, J. (2003). Luces en el laberinto audiovisual. En I. Aguaded (Ed.), Educación en medios: Perspectivas y estrategias. . Huelva: Grupo Comunicar.

Plowman, L., y McPake, J. (2013). Seven Myths About Young Children and Technology. Childhood Education, 89, 27-33. https://dx.doi.org/10.1080/00094056.2013.757490

Plowman, L., Stevenson, O., Stephen, C., y McPake, J. (2012). Preschool children's learning with technology at home. Computers \& Education, 59(1), 30-37. https://dx.doi.org/ 10.1016/j.compedu.2011.11.014

Roca, G. (Ed.). (2015). Las nuevas tecnologías en niños y adolescentes. Guía para educar saludablemente en una sociedad digital. Barcelona. Descargado de https://www .observatoriodelainfancia.es/ficherosoia/documentos/4722_d_cuaderno-faros-2015-es .pdf

Rodríguez, I., Gualda, E., Barrero, N., Arjona, A., Checa, J. C., y Rodríguez, A. (2012). La población infantil ante las nuevas tecnologías de la información. Una aproximación a la realidad de los nativos digitales andaluces. Sevilla: Centro de Estudios Andaluces, Consejería de la Presidencia, Junta de Andalucía.

Rojín, N. (2020). Teléfono móvil y niños: ¿cuáles son los peligros? Descargado de https:// www.efesalud.com/telefono-movil-ninos-peligros/

Sotelo, J., Marta-Lazo, C., y Aranda, G. (2012). El derecho a la participación de la infancia en los medios de comunicación . Derecom(11). Descargado de https://dialnet.unirioja.es/ descarga/articulo/4331062.pdf

Telefónica. (2016). Informe de la Sociedad de la Información en España (SDIE).

Toffler, A. (1980). The third wave. New York: William Morrow.

UNICEF. (2011). Child safety online: Global challenges and strategies. Descargado de https:// www.unicef-irc.org/publications/pdf/ict_eng.pdf

Verhellen, E. (2002). La Convención sobre los Derechos del Niño: Trasfondo, motivos, estrategias, temas principales. Amberes (Bélgica), Apeldoorn (Países Bajos): Garant.

Vittrup, B., Snider, S., Rose, K. K., y Rippy, J. (2014). Parental perceptions of the role of media and technology in their young children's lives. Fournal of Early Childhood Research, 14(1). https://doi.org/10.1177/1476718X14523749

Zhong, Z. J. (2011). From access to usage: The divide of self-reported digital skills among adolescents. Computers \& Education, 56(3), 736-746. https://doi.org/10.1016/j.compedu .2010.10.016 